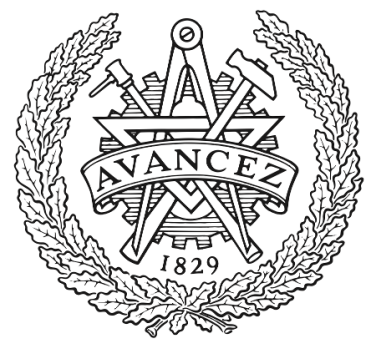

CHALMERS

UNIVERSITY OF TECHNOLOGY

\title{
A topological approach to Mobility as a Service: A proposed tool for understanding requirements and effects, and for aiding the integration of
}

Downloaded from: https://research.chalmers.se, 2023-04-26 15:32 UTC

Citation for the original published paper (version of record):

Sochor, J., Arby, H., Karlsson, M. et al (2017). A topological approach to Mobility as a Service: A proposed tool for understanding requirements and effects, and for aiding the integration of societal goals. 1st International Conference on Mobility as a Service (ICoMaaS), Tampere, Finland, November 28-29, 2017: 187-201

N.B. When citing this work, cite the original published paper. 


\title{
A topological approach to Mobility as a Service: A proposed tool for understanding requirements and effects, and for aiding the integration of societal goals
}

\author{
JANA SOCHOR* Chalmers University of Technology, Sweden, RISE Viktoria, Sweden // \\ jana.sochor@chalmers.se \& jana.sochor@ri.se \\ HANS ARBY UbiGo Innovation, Sweden // hans.arby@ubigo.me \\ MARIANNE KARLSSON Chalmers University of Technology, Sweden // mak@chalmers.se \\ STEVEN SARASINI RISE Viktoria, Sweden // steven.sarasini@ri.se
}

\begin{abstract}
The purpose of this paper is to shed light on the concept of MaaS and what characterizes a 'MaaS service', as well as to propose a topology of MaaS as a tool for facilitating the discussion of MaaS, enabling the 'comparison of' different services, understanding MaaS' potential effects, and aiding the integration of societal goals into MaaS services. Based on a literature review analyzing existing definitions, and an expert workshop identifying key aspects and ascertaining service differentiations accordingly, the resulting proposed topology consists of MaaS Levels 0 to 4 as characterized by different types of integration: 0 no integration; 1 integration of information; 2 integration of booking and payment; 3 integration of the service offer, including contracts and responsibilities; 4 integration of societal goals. The levels are described in terms of their added value and further discussed regarding implications for business, society, users, and technical requirements. Then, a deeper discussion also delves into the potential in expanding upon Level 4 and ways by which services and societal goals can become more fully integrated. The proposed topology adds clarity to the discussion of such a trending topic and enables the positioning of services along the MaaS spectrum. It also deepens the understanding of why MaaS can take time to establish, and can help support the development of action plans in terms of what needs to be done depending on what type of MaaS one wants to develop. Further analysis is desirable regarding the possibilities and problems linked with the different levels of MaaS. Such an analysis is key to understanding which effects can be achieved via the implementation of different levels of MaaS services in terms of e.g. social, economic and ecological sustainability, and business potential.
\end{abstract}




\section{Introduction}

Mobility as a Service (MaaS) is often described as an emerging strategy to reorganize transport in order to tackle mobility and sustainability challenges via offering an alternative to private vehicle ownership. It may do so by, for example, combining different types of mobility services as part of a single, seamless offering that is made available to users via subscription-based smartphone applications (Beutel et al., 2014; Goldman and Gorham, 2006; Sochor et al., 2015). However, there is currently little agreement on a 'definition' of MaaS, on what makes a service a 'MaaS service', or on how to 'compare' MaaS services. Additionally, MaaS is also commonly referred to using the rubrics 'combined' or 'integrated' mobility services, etc. Is MaaS definable, and are these concepts - MaaS, combined mobility, and integrated mobility - the same, or are there differences?

As envisioned, MaaS represents a radical innovation that could potentially revolutionize the transport system, both in terms of passenger and goods transportation. Generally, when radical innovations emerge, there is an initial 'fluid' phase that is characterized by experimentation with multiple competing product/service designs (Abernathy and Utterback, 1978). At this stage, uncertainty prevails and the applications of the innovation in question are unclear. Uncertainty is resolved in a later, transitional phase, as the market consolidates to select a dominant design (ibid). The fluidity of MaaS poses at least two problems. First, as the hype grows, and as increasing numbers of practitioners engage with MaaS, questions remain about 'what MaaS is'. Yet defining the MaaS concept in terms of the content of the service and its applications can be considered, at the present, fluid stage of development, an unwise and premature undertaking. Second, the fluidity of the concept creates challenges in terms of governing a transition to a MaaS-based transport system. If we do not know what MaaS is, how can we know what a MaaS-based transport system can or will deliver in terms of sustainable outcomes? One way to deal with this uncertainty is to develop a characterization of MaaS that embraces the fluidity of the concept.

Hence the purpose of this paper is to develop a topological approach to characterizing the MaaS concept in order to: 1) facilitate more meaningful discussions of the MaaS concept, 2) enable the 'comparison of' different services, 3) understand MaaS' requirements and effects in terms of society, business, users/ customers, and technology, and 4) aid in the integration of societal goals. The paper accomplishes this via a literature review and a multi-stakeholder workshop of MaaS experts, resulting in a proposed topology, which is further discussed and analyzed. 


\section{Motivation and Method}

In light of the current discussion of what MaaS is (or is not) and what characterizes a 'MaaS service', and after many requests from third parties regarding definitions and classifications, the authors decided to analyze the concepts and services and propose a topology to answer these questions. A topology also provides added value in terms of: adding clarity to the discussion of such a trending topic; being able to promote the concept and position a service within the MaaS spectrum; and, when discussing with decision-makers, being able to explain why MaaS can take time to establish by identifying various barriers and enablers for the different topographical levels, and supporting the development of action plans regarding what needs to be done depending on what type of MaaS one wants to develop.

First, a literature review looked at existing definitions of MaaS and similar concepts in order to identify commonalities and differences (Karlsson, 2016, in Swedish), which is summarized in the next section. Second, a multi-stakeholder workshop was held in order to structure the topology. The workshop took place in November 2016 in Gothenburg, Sweden, with seven experts representing the following MaaS stakeholder types: MaaS operator, transport service provider, researcher, and funder (strategic innovation program). Workshop participants were to: identify relevant aspects of MaaS; analyze existing MaaS or similar services in terms of the identified aspects; and finally, define and describe MaaS levels, as well as place services at the best matching level. Results from both the literature review and the workshop are presented below, cumulating in the proposed MaaS topology and auxiliary discussion.

\section{Results: Literature Review of Concepts and Definitions (Karlsson, 2016)}

\section{Combined Mobility (CM)}

Several organizations use the concept of 'combined mobility' (e.g. UITP, 2011; Samtrafiken, 2017; Västtrafik in Smith et al., 2017), which tends to focus on combining modes in general, perhaps with the facilitation of planners, purchasing functions, etc. The definitions of CM are typically broad - along the lines of 'smart services, from planning to purchasing' which may complement public transport (PT) or which may entail not needing to own a private car - leaving open what such services can entail, and thus lacking guidance as to how to achieve such services, e.g. how to combine modes.

\section{Mobility as a Service (MaaS)}

The MaaS concept tends to focus on the (aspects of the) service and not the modes, and sometimes brings in the term 'integration' (e.g. Hietanen, 2014; Kamargianni, 2015; König, et al., 2016; MaaS Alliance, 2017; Trafikverket, 2016; Transport Systems Catapult, 2016). Many well-established phenomena, e.g. carsharing and taxis, can be described in terms of mobility services, but definitions of the 'new' MaaS concept also include other significant elements, such as customers' needs, personalized/tailored and comprehensive solutions, an interface, a mobility platform, integrated payment, a contract, a service offer, a business model, a service provider, etc. The aspects of goods transport (MaaS Alliance, 2017) and sustainability (MAASiFiE project, König et al., 2016) do appear, albeit rarely. 
Integrated Mobility Services (IMS)

The concept of Integrated Mobility Services (IMS) is often used in limited reference to integrated information services, i.e. services that integrate information about different modes and from different service providers. This is in a way unfortunate, as this concept could potentially best capture the central elements of these 'new' mobility concepts (cf. the previous section on MaaS). Broader definitions of IMS (e.g. K2, 2017; MuktharLandgren et al., 2016) tend to emphasize integration of various services in terms of e.g. multimodality, information, payment, and even other related services (deliveries, repairs) via a single/common interface.

\section{Conclusions from the literature review}

There is currently no established definition of MaaS (or CM or IMS), and, as discussed above, it is likely premature to provide 'one definition' at this early stage of MaaS development. Different descriptions and definitions highlight some common and some different central elements, although, no matter the term, it is about:

- Offering a service with customer/user/traveler transport needs as the main focus;

- Offering mobility rather than transport:

- Offering integration of transport services, information, payment and ticketing.

In terms of integration, there needs to be a clearer characterization of different types of integrated services. The challenges faced in the development of integrated services are at least partially related to which types of service elements are to be integrated and to which degree. Despite this, and although various analyses have explored barriers of MaaS (e.g. Holmberg et al., 2015; Mukthar-Landgren, 2016; Sochor et al., 2016a; Transport Systems Catapult, 2016), there is not yet any thorough analysis of the connections between the different types of integrated services and the services' challenges and potentials. Integration can, for example, comprise:

- Integrated information services / multimodal travel information. This, together with integrated payment services, can be considered MaaS' 'core';

- Integrated booking or ticketing, e.g. a 'smartcard' or a mobile app that can provide access to different modes;

- Integrated payment or invoicing;

- Organizational integration. Collaboration between different transport providers (car- and bikesharing, taxi, bus, train, etc.) is a prerequisite for integrated mobility, but how that collaboration occurs will differ between MaaS services.

- Bundling, which entails e.g. a subscription to trips with different modes. This type of integration has so far been the exception rather than the norm, but this may change in the future. Analyses of the success factors of the UbiGo pilot in terms of both customer satisfaction and behavioral change showed the importance of developing the service and its offer to the customers (Sochor et al., 2016b). 


\section{Results: Workshop and the Development of the Proposed Topology}

During the workshop, aspects of different perspectives - societal, business, user/customer, and technical were first identified and discussed, and then collectively narrowed down to a limited number of key aspects (underlined below) in terms of both overall importance and differentiation in service levels (i.e. how do different services differ from each other). Due to time constraints, the workshop did not further delve into more specific stakeholder perspectives, e.g. employers, tourism, housing.

From the societal (or policy) perspective, the aspects considered most relevant were the effect on: private car ownership (current and potential), private car use (congestion and emissions), use of resources (materials, energy, etc.) and existing infrastructure, sustainable accessibility, urban planning and, in the long term, a city's attractiveness and livability, management of traffic and mobility, attitudes and awareness, equitable access (social and geographical), innovation, employment, and, in the future, automated vehicles.

For business, the following were considered important: new customers (number and type, i.e. new markets), new business models, bundling and pricing, becoming a market player, reduced costs (e.g. recruitment, support, management), integration costs, changes in mode use, influencing use, exclusivity (competitively neutral), the customer relationship and 'owning' the customer, branding, contracts, burden of responsibility, liability and guarantees. Certain aspects may be more or less important if the MaaS service is a 'brokerage' versus a mobility marketplace.

From the user/customer perspective, identified important aspects included: how well the service meets one's entire mobility needs (including accessibility and door-to-door solutions), what transport services are included and where they are located (breadth of service), bundling/packaging, flexibility (easy to modify, minimal lock-in effects, etc.), low-risk trialability, cost and price worthiness, burden of responsibility, liability and guarantees, customer support, personalization and customization, decision support (e.g. travel planning), ticketing and payment solutions (easy to book/modify/authenticate and pay), usability (both the interface and how easy it is to understand the offer, pricing, etc.), and data security and protection (ownership, sharing, etc.). For B2B, even easy administration and improved accessibility for employees, customers and visitors.

From the technical perspective, the following were identified as relevant: information/planning function at different levels (a) 'only' centralized information, b) multimodal travel planner, and c) assistant i.e. taking one's schedule into account), payment solutions, APIs, platforms (both front- and back-end solutions), data analysis, integration with existing systems, and user interface.

Next in the workshop, participants identified examples of MaaS or similar services, and, to the best of their knowledge about specific services, attempted to break down how the services differed based on the above, identified key aspects (underlined); see Figure 1. Among existing services were identified: travel planners (with or without real-time information), travel planners with ticketing and payment functions (e.g. Moovit), travel planners with booking and payment functions (e.g. SMILE), mobility marketplaces (e.g. in the Netherlands), 'public transport plus' (e.g. Hannover Mobil), and 'MaaS operators' (e.g. UbiGo, Whim/MaaS Global). For comparative purposes, a unimodal service (Uber) was included.

Regarding Figure 1. This figure is mainly based on the perspectives of the customer, provider and business, as, if a service does not deliver value to the customer or provider, and if the value cannot be captured by the business, then the service is not particularly relevant or sustainable. Regarding the two, isolated ' $\mathrm{x}$ ' marks for Hannover Mobil and SMILE under 'pricing models a) rebates', rebates alone do necessitate some type of 
collaboration above and beyond commissions, but they are perhaps not enough to qualify as a pricing model and could potentially be moved to a special case of payment integration. Also, note that the top row (policy) lacks ' $x$ ' marks, an area of particular relevance for public actors to work within. How does one create the right conditions for mobility services to achieve the desired effects? This is where integration of public transport modes will be highly relevant, as these contracts can contain more than the usual commercial conditions.

\begin{tabular}{|c|c|c|c|c|c|c|c|}
\hline Integration Service & Quixxit & Moovit & $\begin{array}{l}\text { Hann. } \\
\text { Mobil }\end{array}$ & Smile & Moovel & $\begin{array}{l}\text { Whim/ } \\
\text { UbiGo }\end{array}$ & Uber* \\
\hline \multicolumn{8}{|l|}{$\begin{array}{l}\text { Policy / goals: } \\
\text { a) information } \\
\text { b) collaboration \& incentives } \\
\text { c) procurement }\end{array}$} \\
\hline $\begin{array}{l}\text { Information: a) centralized } \\
\text { b) multimodal } \\
\text { c) assistant }\end{array}$ & $\begin{array}{l}x \\
x\end{array}$ & $\begin{array}{l}x \\
x\end{array}$ & $\begin{array}{l}x \\
x\end{array}$ & $\begin{array}{l}x \\
x\end{array}$ & $\begin{array}{l}x \\
x\end{array}$ & $\begin{array}{c}x \\
x \\
(x)\end{array}$ & $\mathrm{x}$ \\
\hline $\begin{array}{l}\text { Booking, ticketing, } \\
\text { authentication }\end{array}$ & & $x$ & $x$ & $x$ & $x$ & $x$ & $x$ \\
\hline Payment & & & $\mathrm{x}$ & $x$ & $x$ & $x$ & $\mathrm{x}$ \\
\hline Responsibility, support, etc. & & & ? & $?$ & ? & $x$ & $x$ \\
\hline $\begin{array}{l}\text { Pricing models, etc. } \\
\text { a) Rebates, etc. } \\
\text { b) Bundling / subscriptions }\end{array}$ & & & (x) & (x? & & $\begin{array}{l}x \\
x\end{array}$ & \\
\hline Brand / customer relationship & & & & & $(X)$ & $x$ & $(X)$ \\
\hline Breadth $(\mathrm{nr}$ of services $=\mathrm{n}$ ) & ? & 1 & 5 & $5+$ park & $5 / x$ & $3 / 5$ & 1 \\
\hline P2P - producer \& consumer & & & & & & & $\mathrm{x}$ \\
\hline
\end{tabular}

Figure 1: Differentiation of services according to identified key aspects.

* Uber, a unimodal service, is included for comparative purposes.

In Figure 1, one can make some differentiations (illustrated by colored clusters in the figure) based on contracts, sharing of risk, responsibility to the customer, and to what degree a service is perceived as a 'unified' service versus a combination of services. From this differentiation, one way to develop a relatively simple topology for MaaS is to start with the clusters as different levels of integration (see Figure 2) and then add layers of nuance e.g. number of modes $(n=4)$, information functionalities ( $b=$ travel planner), etc.

Figure 2 presents the proposed MaaS topology with Levels 0-4 describing varying levels of integration (further discussed below): 0 no integration; 1 integration of information; 2 integration of booking and payment; 3 integration of the service offer, including contracts and responsibilities; 4 integration of societal goals. Before the discussion of the levels, note that one level is not necessarily 'better' than another, as it depends on the customer and his or her needs. However, potential societal effects and business potential are related to the levels, as is which type(s) of actors may run the service. Second, the levels are not necessarily dependent on each other (e.g. the UbiGo pilot was a Level 3 service that more or less lacked Level 1 functionality outside of pricing information). As for matching services to levels, there are always issues of interpretation; e.g. does one classify multimodal public transport with a travel planner and some degree of integrated ticketing/ payment, e.g. Västtrafik in Gothenburg, as Level 0 or as Level 2? 


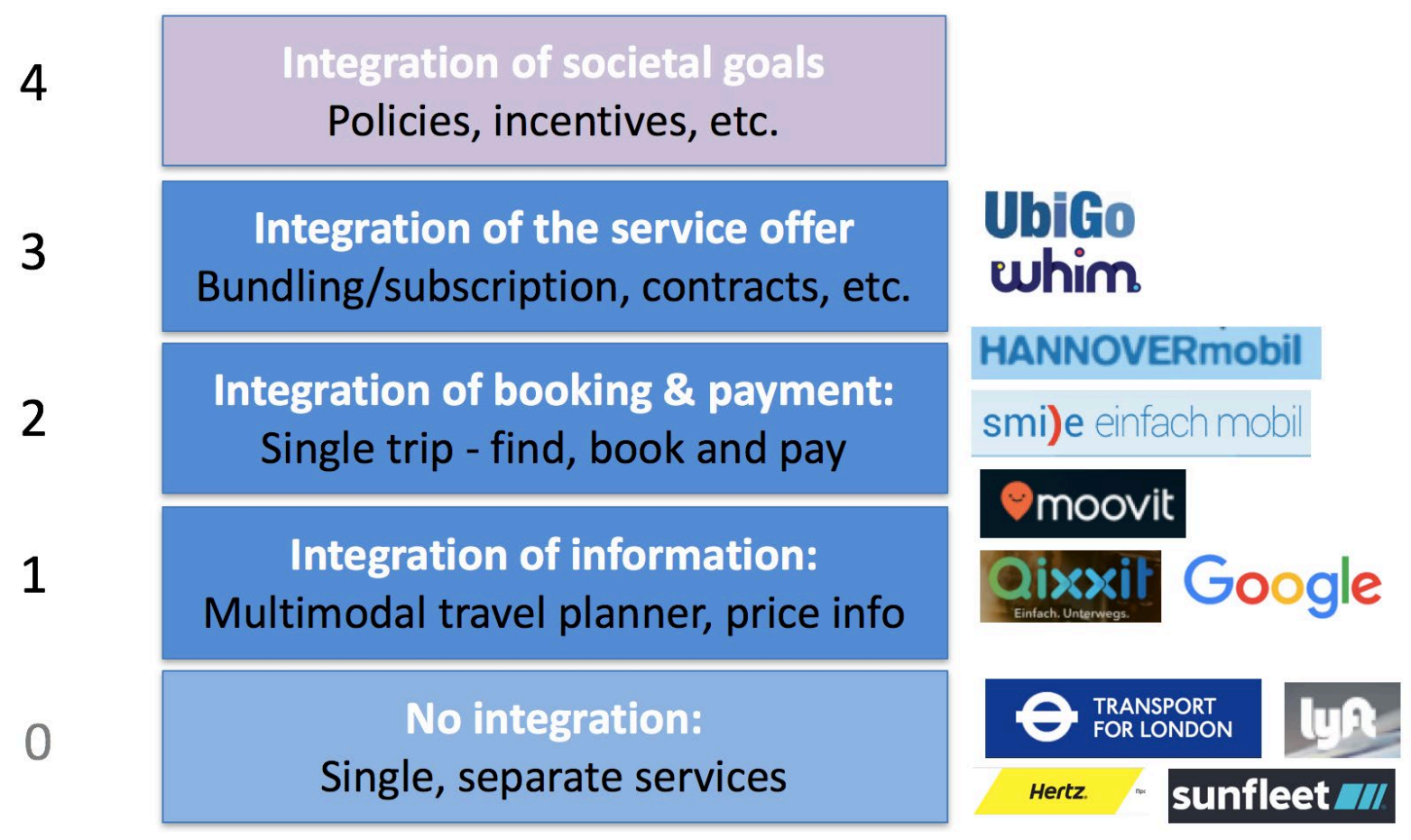

Figure 2: Proposed topology of MaaS including Levels 0-4 (left) and examples (right)

\section{Explanation and discussion of MaaS topology levels}

Level 1

This level represents integration of information, which can be further classified by functionality, as in Figure 1 above, according to a) 'only' centralized information, b) multimodal travel planner, and c) assistant. The added value of Level 1 is decision support for finding the best trip. It has a single trip focus and has users rather than customers. Today, most travel planners or other types of mobility information sites or apps are financed by ads or taxpayers' money. The end users are typically not prepared to pay for travel information, targeted or not, no matter the perceived value.

Transport service providers contribute by supplying open, standardized data for free, which is the case for many public transport agencies. The market will most likely be controlled by a few global players with user bases large enough to attract advertisers, e.g. Google, but there is a clear niche for local, publically operated travel planners and traffic information sites. With a large online user base, the information that global actors collect can be sold to cities for traffic management or infrastructure planning, which is an already established revenue source for such actors. It will however be hard for small companies to keep up, as users more and more will expect 'smart' travel assistants that integrate both personal planning information and relevant data from a broad spectrum of sources. The aggregated information can also consist of price and reservation information and, by forwarding a user to the chosen provider, an 'information market platform operator' has the chance to get a small commission. A Level 1 operator will not be responsible for the quality of the service about which it provides information, and in a legal sense not for the information itself. However, users will turn away if they find (or perceive) that the information cannot be trusted or is hard to understand. 
Level 2

This level represents integration of booking and payment. A Level 2 service focuses on single trips and could be a natural extension to a travel planner, adding public transport ticketing, taxi, or other transport services where possible. In fact, a booking and payment service needs to tie in to a travel planner or some other information service to identify options. Level 2 is sometimes referred to as a bottom-up approach (Architura, 2017).

The added value of Level 2 is to offer users easier access to services, i.e. a one-stop shop where the user can find, book, and pay with the same app (e.g. with a preregistered payment card), and for the transport service providers to be exposed to more customers. This level can be used by registered and/or ad hoc customers depending on the mode (e.g. carsharing requires registration), or perhaps by third parties such as a brokerage. A Level 2 service will make travel easier for those who are already multi/intermodal, but the offer is probably not comprehensive enough to make households to sell their first or second car and, in that way, create new customers.

Although transport service providers gain a cost-effective exposure to the user base, since they will be offered side by side with competitors, the value will be highest for new, small, or niched services that can win market shares. It is possible that some of the more established suppliers will be less interested in being part of a 'mobility bazaar', especially if it comes with a cost, but this of course depends on how dominant the service is. The cost and complexity of integrating many suppliers can be high, depending on the level of standardization. More suppliers also means more contracts. If the service/platform is operated by a public entity, e.g. a public transport authority, it will likely need to be open to all suppliers or be subjected to a quite complicated procurement process.

The Level 2 operator takes responsibility for valid tickets, accurate bookings, and the purchase, but not for the actual travel services. The revenue will come from brokering fees, commissions, and/or from fixed supplier memberships. It is unlikely that users will be willing to pay extra for the assistance in buying a trip if is not combined with some extra service. Despite the low margin, users may expect the operator to take responsibility for the services they in fact have bought from the operator (even when supplied by a provider), thus a Level 2 operator may need to offer first-line support. Low margins, high cost of integrating many services, and cost of first-line support can make it hard to run a Level 2 service - as a separate business, that is. It could however add value to an already existing, non-mobility-based business. If hotels, event companies, shopping malls, etc. could integrate transport into their offer to their customers, the perceived value of their service may be much higher than the cost of integration. One service to include in tickets, campaigns, and other travel or rental services is public transport. In that case commission is not really of any importance, which means that there may be a niche for a B2B aggregator; a clearinghouse that offers easy access to multiple transport services for businesses. It would be like Amadeus for air travel, but with much smaller transactions, and many more and local suppliers, often with different price models. Like an information service with a large user base, aggregated data on users' behavior may perhaps be sold to cities for traffic and mobility management. In addition, an integrated service involving economic transactions can also be used to mediate incentives for choosing more sustainable modes of transport, changing travel times to off-peak hours, etc. 
Level 3

This level represents integration of the service offer, including contracts and responsibilities. The added value of Level 3 is the comprehensive alternative to car ownership, with a focus on the customer's complete mobility needs, and the transport service providers' increased attractiveness to customers they cannot reach as single services. The Level 3 service is bundled, possibly subscription-based, and there is full, two-way responsibility from end user to supplier and vice versa. It is most likely financed by the bottom-line difference between the repackaged services and the volume agreements with the transport service providers.

A Level 3 MaaS service typically focuses on the total need of a household - it is about getting from morning to evening, Monday to Sunday, and spring to winter, rather than single trips from A to B. It is positioned towards offering a comprehensive alternative to car ownership in order to attract customers with larger mobility budgets and willingness to pay for quality and ease of use. It involves a mutual commitment, at least on a monthly basis. As the service is bundled in some way, MaaS should, in this case, be read as Mobility as

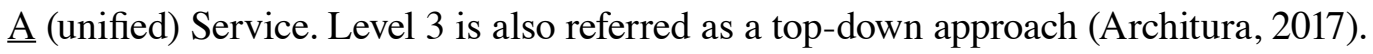

As the MaaS operator takes responsibility for the service delivered to its customers - and for its customers towards the suppliers - it is more than a broker or an open marketplace. The MaaS operator typically works more closely with one preferred supplier per mode in order to also create value for the suppliers and, with that, better deals for its customers. For example, running a carsharing operation is a tight business; if the cars at a site are used too little, they generate a loss, but if the usage is too high, the users will complain and the company will need to add a car (that may be used too little). If the MaaS operator can grow the total customer base and increase the overall usage of the shared cars, this could mean the difference between profit and loss.

The MaaS operator's business is based on a 'swings and roundabouts' principle, i.e. some trips or modes are resold with high margins and some at a loss. The pricing is non-transparent - what the customer pays to the MaaS operator is not directly linked to what the operator pays to the supplier, and the price models can be different from what the suppliers themselves market to their own customers. It is much like an allinclusive charter trip as opposed to the travel agency approach in Level 2, as the traveler does not know the cost for the separate items (flight, hotel, dinner, tours, etc.). For an operator that is skilled in negotiation and understanding customer needs, this opens up for a higher average margin. The bundled service could also be offered to companies as mobility packages to employees.

In a Level 3 service, an ICT-platform is needed to run the business, but in a Level 2 service, the platform is the business. Interestingly, the complexity of the technical integration can be lower for a Level 3 service than for a Level 2 service due to fewer suppliers and less interaction. A Level 1 information service could be more or less a common, global business, as long as there exists some standardized open data. A Level 2 service needs local presence due to more interactions and business agreements with regional or local suppliers. A Level 3 service is local - it needs to find the best supplier of each mode with whom to develop the service, and it needs to find politically acceptable contract models with the regional or local public transport authorities. However, the platform can be shared among networked operators, also opening up for roaming, where customers in one local service can use their native mobility subscription when visiting other cities. 
Level 4

This level represents integration of societal goals. The added value is reduced private car ownership and use, a more accessible, livable city, etc. Incentives are implemented in the MaaS service (or implemented in individual services, as a Level 4 approach could be integrated at any level), reflected by e.g. how well local, regional, and/or national policies and goals are integrated into the service.

The public authorities on a city, regional or national level can influence the societal and ecological impacts of mobility services, i.e. influencing users' behavior by setting conditions for the operators so that they will create incentives for desired behavior. This applies to both individual transport service providers and MaaS operators. Two important public actors are cities that dictate the use of infrastructure and public space, and public transport agencies that often control the 'backbone' of mobility. In the long run, cooperation with these actors is a 'must-have' for potential MaaS operators and the transport service providers. For public actors, their monopoly position should be used to make sure mobility solutions not only fulfill citizens' needs, but the city's goals as well. For instance, a public transport agency can set a hard, but wide framework for the reselling and repackaging of public transport. A city can also use dynamic road charging in dense areas, something that will be crucial if cheap, self-driving taxis start to win over public transport users. A MaaS operator may need to share non-sensitive user data for city or traffic planning purposes, reach a certain conversion rate, or forward incentives such as benefits for shifting to off-peak public transport trips.

Mixing public, often subsidized, services with commercial services into customizable packages poses different challenges. Public transport is a one-size-fits-all service with non-flexible price models, while an attractive MaaS offer needs to be perceived as a unified, flexible service. It is the public transport service that needs to be integrated rather than the existing public transport 'products' such as single tickets or monthly cards. To be politically acceptable, resellers need to prove that the pricing of public transport, as part of a MaaS service, is revenue, tax, and price neutral compared to the direct sales of tickets. A MaaS service run by a public transport agency will experience the same problem - if the service should be attractive enough to compete with car ownership.

It is also important to understand that a business model is connected to the organization that owns it. The possible offers, revenue streams, relationships, partnerships, and agility all depend on who runs the service, as do the effects on the transport system. Will MaaS make it easier for public transport users to use a car or for car owners to use more public transport? Level 4 is really about how to balance the demands on transport service providers and MaaS operators against the possibilities to run a 'profitable enough' business. This means developing contractual models for private-public cooperation, and understanding how changes in a policy framework will affect users' behavior with transport service providers and MaaS operators as intermediaries.

\section{Achieving a transition to a MaaS-based transport system}

MaaS has the potential to revolutionize the way we travel. The proposed transformation is radical in scope, and may be described using the notion of a socio-technical transition. The latter is defined as "...a gradual, continuous process of change where the structural character of a society (or a complex sub-system of society) transforms" (Rotmans et al., 2001). A transition to MaaS may be considered sustainable if MaaS contributes to the fulfilment of societal goals, such as the need for decarbonization of the transport system, reduced congestion, innovation, and better accessibility. In other words, a transition to MaaS services that integrate 
societal goals (Level 4) may be considered sustainable. In this section, we address the question of how a transition may be governed, such that barriers and obstacles to change are overcome, by referring to the field of transition management. The latter outlines four activities that are key to the governance of sustainable transitions: strategic, tactical, operational, and reflexive activities (Kemp and Loorbach, 2007; Loorback, 2007, 2010).

- Strategic activities are collaborative, multi-stakeholder processes, which aim to ensure that long-term visions (i.e. societal goals) are shared and embedded among collectives.

- By contrast, tactical activities serve to link individual actor strategies to the shared long-term visions created via strategic activities, aiming to overcome short-termism within different societal sectors (e.g. politics, business). They also aim to tackle the difficulties in implementing solutions by acknowledging complex sources of inertia within regimes, and directing activities such as corporate political action and lobbying towards the reformation of such structures.

- Operational activities aim to link everyday activities such as innovative experiments to long-term visions, broader policies and change agendas.

- Reflexive activities include the ongoing monitoring, assessment and evaluation of policies and practices as a means to revise overarching visions and plans where necessary.

The current 'fluid' phase of MaaS development, which is characterized by experimentation with multiple competing product/service designs (Abernathy and Utterback, 1978), we argue that operational, tactical, and reflexive activities are presently the primary focus for MaaS practitioners (and other stakeholders) at Level 4. Generally, operational activities aim to link everyday practices (e.g. innovative experiments conducted by MaaS practitioners) to broader visions and change agendas. Here the term 'vision' refers to relevant societal goals, including transport policy objectives (decarbonization, reduced congestion, improved accessibility, innovation, etc.) or other societal trends such as digitalization and the shift to a more circular economy. By contrast, tactical activities: link individual actor strategies to shared long-term visions; aim to tackle the difficulties in overcoming institutional barriers to change; and lobby for and experiment with new institutional arrangements. The overarching point is that the capacity for MaaS to support transport policy objectives and other societal goals is essential to its success. Operational, tactical, and reflexive activities are all needed to demonstrate this potential, and require engagements from MaaS practitioners within the public and private sectors.

In terms of operational and reflexive activities, there are several things MaaS practitioners can do to link innovative experiments to broader visions and political goals. One example is to demonstrate how MaaS services (including pilots) contribute to reduced congestion and emissions, improved accessibility, and sustainable travel behavior of users. A further example, as noted in previous sections, is to show how nonsensitive user data generated via MaaS can be sold to cities for traffic management purposes to improve the sustainability of the transport system. In future, developments in connected vehicles and other digital technologies could allow for real-time traffic management of 'smart' cities, allowing for further sustainability gains. Demonstrating the benefits of experiments such as these can help to garner financial and political support for a transition to a MaaS-based transport system. Operational and reflexive activities may focus on other types of innovative experiments for the same purpose, including: the further integration of transport modes within MaaS business models; the scaling of MaaS business models to new geographical areas; roaming; the integration of incentives for sustainable travel behavior into MaaS services (i.e. incentives such as nudging and gameification to promote shared mobility and sustainable modal choices); the further introduction of environmentally benign technology into vehicle fleets (e.g. electric drives) as a means to 
reduce transport emissions; and so on. Operational activities ensure that experiments and innovations are directed towards the resolution of societal problems, and reflexive activities evaluate and assess the way in which MaaS generates sustainable value for different societal stakeholders.

In terms of tactical activities, transition management involves making it clear how the strategies of individual MaaS practitioners can collectively contribute to the sustainable development of the transport system. Similar to operational activities, linking individual strategies in the private and public sectors to broader visions provides MaaS with credibility and legitimacy among societal stakeholders, and can help to garner financial and political support. In practice, this means that MaaS practitioners should establish organizational strategies, goals and targets that collectively aim to improve the sustainability of the transport system (e.g. by attracting $X$ numbers of new users, our company aims to reduce transport system emissions in city $Y$ by $Z \%$ in five years).

MaaS practitioners can engage in a further type of tactical activity, which is to engage a set of key stakeholders with the mandate to provide the types of support necessary to allow MaaS to flourish. In practice, these actors may be financial investors, who are willing to provide capital to support successful business models; civil society organizations that can champion MaaS by shaping public opinion; and public authorities, who are willing to create a set of supportive institutional arrangements given the demonstrated sustainability benefits of MaaS. Examples of such institutional arrangements include the revision of fiscal policies and the redistribution of subsidies on a municipal, regional, or national level. Public authorities can also can also influence the social and ecological impacts of mobility services by placing demands on operators to create incentives for desirable travel behavior; and they can support the diffusion of MaaS by providing exemptions from congestion charges, altering parking regulations, allowing shared cars to travel in bus lanes, etc. Further, public authorities can integrate MaaS into local transport policy objectives by, for example, using dynamic road charging in dense areas.

In practice, mixing public, commonly subsidized, services with commercial services into customizable packages poses significant challenges. Public transport is a one-size-fits-all service with inflexible price models, whereas an attractive MaaS offer is designed as a unified, flexible service, which may be commercially driven. To gain acceptance, MaaS practitioners must demonstrate to one another that their business strategies and practices will not encroach on others' customer base and brand. Also, (particularly commercial) MaaS operators must ensure that public transport is priced at a revenue-, tax- and price-neutral level compared to the direct sales of tickets. In order to overcome these types of barriers to collaboration, it may be necessary to engage third-party actors (possibly public authorities) that can act as neutral gatekeepers to help overcome existing levels of fragmentation between and protectionism/risk aversion among MaaS practitioners. Fragmentation is not limited to MaaS practitioners: cities have large role to play in that they dictate the use of infrastructure and public space; and public authorities commonly control the 'backbone' of mobility. Private sector engagement is also needed to unlock the innovative potential of MaaS, which spans the transport, telecom and energy industries (Spickermann, et al. 2014). In situations where existing stakeholders and practitioners cannot overcome the types barriers described above, relevant third parties may need to step in as neutral orchestrators of collaboration. To summarize, engaging different types of stakeholders is critical for two reasons: 1) it can provide a platform for MaaS practitioners to lobby for and experiment with new institutional arrangements; and 2) it can aim to tackle the difficulties in overcoming institutional barriers to the development and diffusion of MaaS. 


\section{Concluding remarks}

There are currently many examples of different mobility services, from multimodal travel information (including park\&ride, parking, etc.) to integrated ticketing services, to 'MaaS operator'-type services. However, lumping all these services together under one loosely defined concept such as MaaS creates confusion and potentially undermines the concept as it can then be perceived as merely the latest buzzword; a new name for the same old thing. As illustrated and explained above, not all services are 'equal' in the MaaS topology. The innovation in MaaS, but also the challenge, likely lies not only in the integration entailed in the levels above, but the organizational integration (not least between public and private actors) and the bundling required to achieve Levels 3 and 4. Understanding the MaaS topology and its implications can help nuance the conversation, deepen the understanding of barriers and enablers for different levels, and facilitate the development of MaaS, e.g. in the form of action plans tailored to the intended MaaS level and goals.

Regarding the topology per se, it could be argued that it may be too 'simplistic', as there may exist hybrids between levels, and as pointed out above regarding matching services to levels, there are always issues of interpretation; e.g. does one classify multimodal public transport with a travel planner and some degree of integrated ticketing/payment, e.g. Västtrafik in Gothenburg, as Level 0 or as Level 2?. There may also exist additional aspects that have not been applied to the levels, e.g. geographical context (urban, suburban, and rural MaaS); and Level 4 could potentially be broken down into the three types of sustainability - social, economic, and ecological - and applied in a third-dimensional layer across all levels, including trade-offs between types of sustainability, e.g. accessibility/social and ecological. However, the purpose of developing this topology was not to present an exhaustive and static description of MaaS, but rather to provide a straightforward and dynamic tool as a basis for discussing, understanding, and comparing different types of services, their viability and effects. In other words, we posit that the topology may be a useful fundament for a set of tactical, operational and reflexive activities that can assist in a transition towards a sustainable, MaaS-based transport system.

As a next step in deepening the understanding of MaaS, further analysis is desirable regarding the possibilities and problems linked with the different levels of MaaS, preferably based on thoroughly evaluated case studies, more of which are needed (Karlsson et al., 2017). Such an analysis is key to evaluating and understanding which impacts and effects can be achieved via the implementation of different levels of MaaS services in terms of e.g. social, economic and ecological sustainability, as well as business potential. That is, there is a strong need for reflexive activities that assess and evaluate the utilities of MaaS as an operational phenomenon.

\section{Acknowledgments}

The authors wish to thank the experts who volunteered their valuable time to provide important input during the workshop. The workshop was part of the pre-study "Systems and Services for Mobility" and initiated within DriveSweden, a Strategic Innovation Program launched by the Swedish government to drive the evolution towards a transportation system based on automation, digitization, and servitization. 


\section{References}

Abernathy, W.J., Utterback, J.M., 1978. Patterns of Industrial Innovation. Technology Review, 80, pp. 1-9.

Architura, 2017. Service-Oriented Architecture Methodology: Top Down vs. Bottom Up. http:// serviceorientation.com/soamethodology/top down vs bottom up Accessed 2017-08-24.

Beutel, M.C., Gokay, S., Kluth, W., Krempels, K.-H., Samsel, C., Terwelp, C., 2014. Product oriented integration of heterogeneous mobility services. Proceedings of the 17th International IEEE Conference on Intelligent Transporation Systems (ITSC14), pp. 1529-1534. http://dx.doi.org/10.1109/ITSC.2014.6957650

Goldman, T., Gorham, R., 2006. Sustainable urban transport: Four innovative directions. Technology in Society, 28, pp. 261-273. http://dx.doi.org/10.1016/j.techsoc.2005.10.007

Hietanen, S., 2014. 'Mobility as a Service' - the new transport model? ITS \& Transport Management Supplement. Eurotransport, Vol. 12(2), 2014, pp. 2-4. http://www.fiaregion1.com/download/events/its supp et214.pdf Accessed 2017-03-01.

Holmberg, P-E., Collado, M., Sarasini, S., Williander, M., 2015. Mobility as a Service - MAAS. Describing the framework. RISE Viktoria (formerly Viktoria Swedish ICT), Gothenburg, Sweden https://www.viktoria.se/publications/mobility-as-a-service-maas-describing-the-framework

K2 Swedish Knowledge Center for Public Transport, 2017. http://www.k2centrum.se/ fou-omr\%C3\%A5den/integrerade-mobilitetstj\%C3\%A4nster Accessed 2017-03-01.

Kamargianni, M., Matyas, M., Li, W., Schäfer, A., 2015. Feasibility Study for "Mobility as a Service" concept in London. UCL Energy Institute, London. https://www.researchgate.net/publication/279957542 Feasibility Study for Mobility as a Service concept in London Accessed 2017-03-01.

Karlsson, I.C.M., 2016. Integrerade Mobilitetstjänster. Omvärldsanalys 1:2016. K2 Swedish Knowledge Center for Public Transport, Lund, Sweden.

Karlsson, M., Sochor, J., Aapaoja, A., Eckhardt, J., König, D., 2017. Deliverable 4: Impact Assessment of MaaS. MAASiFiE project funded by CEDR. http:/www.vtt.fi/sites/maasifie/PublishingImages/results/ CEDR_Mobility_MAASIFIE_Deliverable_4_Revised_Final.pdf Accessed 2017-09-18.

Kemp, R., Loorbach, D., Rotmans, J. 2007. Transition management as a model for managing processes of co-evolution towards sustainable development. International Journal of Sustainable Development \& World Ecology . 14, pp. 78-91. http://dx.doi.org/10.1080/13504500709469709

König, D., Eckhardt, J., Aapaoja, A., Sochor, J., Karlsson, M., 2016. Deliverable 3: Business and operator models for MaaS. MAASiFiE project funded by CEDR. http://www.vtt.fi/sites/maasifie/PublishingImages/ results/cedr mobility MAASiFiE deliverable 3 revised final.pdf Accessed 2017-09-18.

Loorbach, D.A., 2007. Transition management: new mode of governance for sustainable development. International Books, Utrecht. http:// hdl.handle.net/1765/10200

Loorbach, D., 2010. Transition Management for Sustainable Development: A Prescriptive, Complexity-Based Governance Framework. Governance, 23, pp. 161-183. http://dx.doi.org/10.1111/j.1468-0491.2009.01471.x

MaaS Alliance http://maas-alliance.eu/european-mobility-service-alliance/ Accessed 2017-03-01.

Mukthar-Landgren, D., Karlsson, M., Koglin, T., Kronsell, A., Lund, E., Sarasini, S., Smith, G., Sochor, J., Wendle, B., 2016. Institutional conditions for integrated mobility services (IMS). Towards a framework for analysis. K2 Working paper 2016:16. http://www.k2centrum.se/sites/default/files/fields/field uppladdad 
rapport/institutional conditions for integrated mobility services ims wp 2016-16 1.pdf Accessed 201703-01.

Rotmans, J., Kemp, R., Van Asselt, M., 2001. More evolution than revolution: Transition management in public policy. Foresight 3, 15-31. http://dx.doi.org/10.1108/14636680110803003 Accessed 2017-09-28.

Samtrafiken, 2017. Förarbete - Swedish Mobility Program (SMP). https://samtrafiken.se/wp-content/ uploads/2017/02/F\%C3\%B6rarbete-Swedish-Mobility-Program.pdf Accessed 2017-03-01.

Smith, G., Sochor, J., Karlsson, I.C.M., 2017. Procuring Mobility as a Service: Exploring dialogues with potential bidders in West Sweden. 24th World Congress on Intelligent Transportation Systems (Montreal, October 29-November 2, 2017).

Spickermann, A., Grienitz, V., von der Gracht, H.A., 2014. Heading towards a multimodal city of the future? Technologial Forecasting and Social Change, 89, pp. 201-221. https://doi.org/10.1016/j.techfore.2013.08.036

Sochor, J., Strömberg, H., and Karlsson, I.C.M., 2015. Implementing Mobility as a Service: Challenges in Integrating User, Commercial, and Societal Perspectives. In Transportation Research Record: Journal of the Transportation Research Board, No. 2536, Vol. 4, pp. 1-9, Transportation Research Board of the National Academies, Washington, D.C. http://dx.doi.org/10.3141/2536-01

Sochor, J., Eckhardt, J., König, D., Karlsson, I.C.M. 2016a. Future Needs and Visions for Mobility as a Service: Insights from European Workshops. Proceedings of the 23rd World Congress on Intelligent Transportation Systems (Melbourne, October 10-14, 2016).

Sochor, J., Karlsson, I.C.M., Strömberg, H., 2016b. Trying Out Mobility as a Service: Experiences from a Field Trial and Implications for Understanding Demand. In Transportation Research Record: Journal of the Transportation Research Board, No. 2542, Vol. 4, pp. 57-64, Transportation Research Board of the National Academies, Washington, D.C. http://dx.doi.org/10.3141/2542-07

Trafikverket, 2016. Report: Underlag till Nationell Strategi och handlingsplan för användning för Intelligenta Transportsystem i Sverige, Remiss version. http://its-sweden.se/itshp/wp-content/ uploads/2016/11/ITSHP 161118 v099.pdf Accessed 2017-03-01.

Transport Systems Catapult, 2016. Mobility as a Service: Exploring the Opportunity for Mobility as a Service in the UK. https://ts.catapult.org.uk/wp-content/uploads/2016/07/Mobility-asa-Service Exploring-the-Opportunity-for-MaaS-in-the-UK-Web.pdf Accessed 2017-03-01.

UITP, 2011. Becoming a real mobility provider Combined Mobility: public transport in synergy with other modes like car-sharing, taxi and cycling. http://www.uitp.org/sites/default/files/ cck-focus-papers-files/FPComMob-en.pdf Accessed 2017-03-01. 